\title{
Os contratempos do espaço: patrimônio cultural imaterial e o Livro de Registro Atividades Econômicas Tradicionais e Notáveis
}

\author{
Los contratiempos del espacio: patrimonio cultural inmaterial \\ y el Libro de Registro Actividades Económicas Tradicionales y Notables
}

\author{
The space's contradictions: cultural heritage and \\ the new form of heritage's registries named \\ "Traditional and Notable Economic Activities"
}

\author{
João Domingues'
}

Palavras chave:

Empreendedorismo urbano

Patrimônio cultural

Rio de Janeiro
Resumo:

O presente artigo" tem como objetivo discutir as intervenções em áreas urbanas centrais e suas conexões com as políticas culturais. De maneira mais específica, pretende-se analisar como a radicalização da mercantilização do espaço urbano cria condições de interferência em processos de reconhecimento e vivência patrimonial. No caso em questão, destaca-se o imbróglio envolvendo o processo de registro no Livro Patrimonial "Atividades Econômicas Tradicionais e Notáveis”, uma novidade nas políticas patrimoniais da cidade do Rio de Janeiro. Ao final, espera-se demonstrar a inexorabilidade das inscrições sociais nas relações espaciais e temporais, carregadas de conflitos discursivos, e sua determinação para a continuidade das expressões selecionadas no novo livro de registros imateriais. 


\begin{abstract}
Resumen:
El presente artículo tiene como objetivo discutir las intervenciones en áreas urbanas centrales y sus conexiones con las políticas culturales. De manera más específica, se pretende analizar cómo la radicalización de la mercantilización del espacio urbano crea condiciones de interferencia en procesos de reconocimiento y vivencia patrimonial. En el caso en cuestión, se destaca el imbróglio envolviendo el proceso de registro en el Libro Patrimonial "Actividades Económicas Tradicionales y Notables", una novedad en las políticas patrimoniales de la ciudad de Río de Janeiro. Al final, se espera demostrar la inexorabilidad de las inscripciones sociales en las relaciones espaciales y temporales, cargadas de conflictos discursivos, y su determinación para la continuidad de las expresiones seleccionadas en el nuevo libro de registros inmateriales.
\end{abstract}

Palabras clave:

Emprendimiento urbano

Patrimonio cultural

Rio de Janeiro

\section{Keywords:}

Urban

entrepreneurialism

Cultural heritage

Rio de Janeiro

\section{Abstract:}

This article aims to discuss spatial interventions in urban areas and their connections with cultural policies. More specifically, it intends to analyze how the increased commodification of urban spaces interferes in recognition processes and cultural heritage's experiences. The objective expression for that question is the contradictions involving the heritage process of historical small business ventures in the city of Rio de Janeiro, including a new forms of heritage's registries named "Traditional and Notable Economic Activities". In the end, it is hoped to demonstrate the inexorability of social inscriptions in spatial and temporal social relations, loaded with discursive conflicts. 


\section{Os contratempos do espaço: patrimônio cultural imaterial e o Livro de Registro Atividades Econômicas Tradicionais e Notáveis}

\section{Introdução}

O presente trabalho dedica-se a interpelar as relações entre a gestão urbana contemporânea, as políticas patrimoniais e as práticas culturais em centros urbanos. Procura-se ressaltar que estas relações se conformam no ínterim das contradições inerentes aos processos de acumulação urbana, incidindo sobre diferentes apropriações, interpretações e interesses que produzem o espaço.

É razoavelmente consensual afirmar na literatura aplicada ao campo do urbanismo contemporâneo que as mudanças estruturais traduzidas como a fase flexível do capital consolidaram um novo modo de administração das cidades, orientado para a promoção do desenvolvimento econômico, explorando vantagens locacionais para oferta de bens e serviços e para atração de capitais financeiros (BRENNER ET AL., 2011; COMPANS, 2004, HARVEY, 2006).

Neste processo a reocupação dos centros urbanos ganha outra importância. Essenciais por sua função habitacional, pela concentração de matrizes empresariais ou equipamentos culturais essenciais à cotidianidade, os centros carregam parte essencial da história que organiza as comunidades políticas a que se referem.

As características deste "retorno ao centro" (SMITH, 2006) se apresentam de forma geral como uma tentativa da resolução de problemas urbanos referentes à estagnação econômica. Assim dito de forma genérica, tenderíamos a supor que este processo conta com parâmetros universalistas de renovação da economia urbana. Mas a forma dominante do padrão financeiro do capital movimenta-se sob outra direção, superando quaisquer didáticas dotadas de eufemismos. A base de investimentos na região central normalmente se concentra em um conjunto bastante estrito de parcelamentos espaciais - os capazes de oferecer maior rentabilidade -, tendo em vista a maximização dos investimentos de certos setores capitalistas.

Relativamente esvaziados, inclusive em sua importância simbólica, os centros veem-se comumente repletos de capitais fixos desvalorizados, sendo facilmente transacionados a preços módicos de mercado. Neste aspecto, o alto grau especulativo do capital que circula o espaço encontra nos centros urbanos "oportunidades" únicas de gerar sobre-valores espaciais, operando em retóricas de superação da degradação espacial, da insegurança e da inércia econômica do uso (HARVEY, 2006).

Neste âmbito a operação de renovação da economia urbana poderá encontrar várias de suas ambiguidades explícitas. Entre as formas de ocupação - por vezes centenárias - e a promoção de condições de rentabilidade ao investimento capitalista, o solo urbano se vê imerso nas tensões entre políticas de conservação ou estímulos à destruição própria da espacialização do capital. A trajetória arquitetônica, seus valores-de-uso, os sujeitos usuários e moradores circundam o processo de retorno como empecilho ou formas ativas da reorientação econômica do espaço.

Neste sentido, as administrações e os viventes das cidades vêm enfrentando desafios de enorme monta, em especial no que concerne às possibilidades de conjugação dos parâmetros característicos da 
urbe - a ideia de diversidade social, por exemplo - à atração e fixação de fluxos financeiros dispersos como condicionante privilegiado para o desenvolvimento econômico urbano.

Como tal, é possível imaginar que certos parâmetros da vida citadina menos propensos à integração social subordinada às exigências da espacialização contemporânea do capital podem ver-se atravessados por dinâmicas conflituosas quanto às perspectivas de continuidade e publicização de seus projetos. A gestão urbana, quando alinhada ao caráter de viabilização da acumulação urbana, pode então conter em sua dinâmica certos obstáculos que, no cumprimento da gestão empreendedora da cidade, acabam por gerar distintos graus de invisibilidade de práticas e de deformação da experiência da diversidade cultural. $E$ neste processo vivências urbanas que encontram o patrimônio cultural podem ser diretamente afetadas. Formas de flexibilização sobre o uso do solo podem criar condições de interferência em experiências patrimoniais, e de forma às vezes menos evidente para as agências e corpos que as representam.

Para este artigo, a materialização deste processo se fará na análise do centro da cidade do Rio de Janeiro, mais especificamente acerca dos imbróglios envolvendo a continuidade de algumas atividades comerciais com larga idade na Rua da Carioca, tendo como tese de fundo as interferências do modelo de gestão urbana caracteristicamente empreendedor (HARVEY, 2006) e seus efeitos para experiências no subcampo do patrimônio cultural. Propõe-se, portanto, a analisar possíveis interações entre as políticas patrimoniais e a gestão urbana contemporânea, em específico acerca das dinâmicas de sobreposição entre interesses privados de acumulação urbana e formas explícitas de intervenção da municipali- dade. Para tal, procurou-se investigar a criação do novo livro de registro patrimonial imaterial intitulado "Atividades Econômicas Tradicionais e Notáveis", uma iniciativa do Instituto Rio Patrimônio da Humanidade (IRPH), órgão criado pelo Executivo municipal para planejar e executar os programas e projetos relativos ao patrimônio cultural (DOMINGUES, 2016).

No caso do Rio de Janeiro é possível ainda destacar as profundas transformações que a cidade vem sofrendo em sua gestão urbana e em sua política de patrimônio cultural, reivindicando, inclusive, aproximações com a gramática particular da economia criativa"l". Por óbvio, o centro da cidade tem chamado atenção nestas novas relações.

O que é notável perceber é que as ações de radicalização da mercantilização espacial do centro da cidade do Rio de Janeiro vêm incorporando interesses de atores públicos ligados à área do patrimônio cultural, e de forma muito peculiar. Se pudemos perceber até a década de 2000 certa preocupação com a dimensão imobiliária e com os conjuntos arquitetônicos e ambientais, a década de 2010 conformará uma conexão entre dimensões imateriais ligados ao campo do patrimônio cultural e a capacidade de geração de um tipo muito especial de sobrevalor espacial (DOMINGUES, 2016).

De certa maneira, hipostasiar um Rio de Janeiro antigo, um território "tradicional", atualiza ao patrimônio cultural condições únicas de sua configuração enquanto um setor produtivo. De forma conexa aos seus ocupantes, o que lhes darão sentido, uma certa "autenticidade" e "veracidade" de sua "tradicionalidade" estarão ocupados em táticas de permanência. No caso a analisar, ver-se-á que a descrição desta ação patrimonial é tamanho novidadeira que implica a criação 
de um livro patrimonial cujo interesse de registro está ligado a atores de atividades econômicas - uma mudança radical de trajetória das políticas patrimoniais, onde se procura atender como princípio protetivo o domínio da posse de um pequeno comércio.

O que se pretende aqui apresentar é um breve relato de uma pesquisa de campo que procurou interpelar as relações mais moleculares que hoje tencionam vínculos entre a espacialização do capital e a especialização do patrimônio cultural imaterial. Ao fim, é cabal perceber que o substrato da fala destes "novos atores tradicionais" está repleto de receios, seja acerca de sua "desconexão" ao tempo presente seja sobre seu medo de exclusão nas atividades laborais.

\section{Rua da Carioca, Rua do Piolho: elementos heterotópicos como fontes potenciais do patrimônio cultural}

Volta-se agora à questão concreta que subjaz à indagação deste trabalho. Para demonstrar como as relações entre a gestão urbana empreendedora e o campo político-cultural fazem-se de forma tensa, analisar-se-á o imbróglio envolvendo as atividades do conjunto urbano imobiliário - e de suas expressões componentes - da Rua da Carioca, no centro da cidade do Rio de Janeiro, em relação à curta trajetória das políticas de patrimônio.

A Rua da Carioca encontra-se como logradouro no limite das Ruas da Assembleia, Uruguaiana, ligando o Largo da Carioca à Praça Tiradentes. Por firmar-se nesta confluência de ocupação da cidade, a Rua da Carioca é um caso exemplar das muitas transformações que o Rio de Janeiro experimentou, desde sua fundação. De maneira ainda mais importante, o estudo da Rua da Carioca em sua atual circunstância igualmente expõe a recente reocupação do centro da cidade do Rio de Janeiro, em sua nova função para a reprodução urbana de tipo único.

Como tal, é possível perceber as flutuações no planejamento da cidade, os resquícios de endurecimento das atividades populares promovidas pela regulação do poder público, a anterioridade das propriedades imobiliárias, as confusas intervenções transescalares, que incidiram sobre a diminuição de importância e pujança econômica da cidade.

Aberta no final do século XVII, próxima aos limites da zona urbana da cidade, a Rua da Carioca - então chamada Rua do Egito - era vizinha ao Morro de Santo Antônio, propriedade da Ordem dos Franciscanos. Sua ocupação começaria no margeamento da propriedade franciscana, e apenas no século XVIII começaram a surgir imóveis do lado oposto. Era a mesma época de construção do Hospital da Ordem Terceira de São Francisco da Penitência.

Em 1741 a rua ganharia outro nome; Rua do Piolho, que remetia à alcunha de um morador especialista em vasculhar cartórios, como "piolho em costura". Apenas em 1848 a Câmara Municipal deu-Ihe o nome de Rua da Carioca, em referência ao trajeto dos moradores na busca de água no chafariz do Largo da Cariocalv .

O lado ímpar da Rua da Carioca foi povoado com imóveis de construções neoclássicas. O lado par remete à fase eclética da arquitetura brasileira, que substituiu as originais, logo no início do século $X X$.

Em fins do século XIX e início do XX, a Rua da Carioca será então capturada pela lógica sanitarista e embelezadora da interferência urbana republicana. Este processo compunha 
concomitantemente dois anseios: capitalizar o modelo estético e memorial do período imperial, inclusive o acúmulo de novas operações urbanas; e preparar a capital da novíssima República para os novos tempos de modernidade. Como tal, é possível perceber que apenas no decorrer do século XX muitas das análises sobre os possíveis aformoseamentos da cidade do Rio de Janeiro seriam de fato levadas a cabo, em especial pelas reformas produzidas no centro da cidade do Rio de Janeiro durante a prefeitura de Pereira Passos (ANDREATTA, 2008). Os efeitos concretos das reformas gradualmente retirariam o uso residencial do centro, deixando-a disponível para o uso comercial. Como tal, a ocupação imobiliária da Rua da Carioca destinou-se quase que exclusivamente a esta funcionalidade.

O lado ímpar da Carioca é ainda hoje formado por construções neoclássicas datadas de meados de 1880, enquanto que as do lado par da rua foram substituídas já na primeira década do século XX, e a rua, alargada. As construções são, em si, alvo de proteção prévia pelo Decreto Municipal n 20.048/2001, do município do Rio de Janeiro, que proíbe a demolição de edificações construídas até o ano de 1937. Este decreto altera artigos do Regulamento de Licenciamento e Fiscalização, de 20 de abril de 1970, e determina que a "demolição e a alteração das edificações construídas até 1937, inclusive, somente serão autorizadas após pronunciamento favorável do Conselho Municipal de Proteção do Patrimônio Cultural do Rio de Janeiro" (RIO DE JANEIRO, 2001).

Este instrumento legislativo, ainda que não contenha em si a mesma qualidade jurídica nem a perspectiva de ação político-cultural dos processos de tombamento, já pôde garantir à Rua da Carioca uma certa permanência de seu conjunto urbano no âmbito municipal. Ademais, os casarios da Rua da Carioca são tombados pelo Instituto Estadual do Patrimônio Cultural (INEPAC) desde 1983, e o conjunto arquitetônico protegido pela Lei $n^{\circ}$ 506 , de janeiro de 1984, que cria a Zona Especial do Corredor Cultural. Como tal, a dimensão imobiliária da Rua enquadra-se numa organização mais ampla do caráter patrimonial municipal, incidindo, inclusive, na restrição ao aumento do gabarito de construções.

Mas o que os decretos, processos e leis que tenham como vínculo a dimensão patrimonial ainda não se mostram precisos diz respeito às garantias de permanência das atividades que conferem o caráter de reconhecimento público a certos capitais fixos dotados da anterioridade necessário à consagração como patrimônio cultural.

Como já citado, a Rua da Carioca mantém em si suas peculiaridades espaciais. Interligando o Largo da Carioca à Praça Tiradentes e bem próxima à Lapa, a Rua ilustra as experiências heterotópicas de informalidade cotidianas (LEFĖBVRE, 1999) e as ondas de transformações espaciais do centro da cidade.

Se o bairro da Lapa é hoje reconhecido como um dos locais onde a produção cultural da cidade do Rio de Janeiro ganha aspectos de nova profissionalização e a Praça Tiradentes acompanha a indução de investimentos públicos para a ampliação de empreendimentos criativos, a outra margem da Rua da Carioca aponta ainda para outros vínculos territoriais.

O Largo da Carioca é ainda um local de experimentos espaciais muito especiais. O Largo sintetiza no enclave certos vínculos que todas as cidades mantêm com o mundo do trabalho, em especial àqueles que não dispõem das mesmas quantidades de capitais (eco- 
nômicos, culturais e sociais) hoje convencionados como pré-requisitos à sua inserção em rotinas formais. Por óbvio estas se consolidam em tensão, quando a plêiade de sujeitos, que hoje não estão inseridos no mercado de trabalho formal, mostram-se muitas vezes desprotegidos às dimensões de ação regulatória espacial da "ordem pública".

Ademais, o Largo é também um dos marcos da história urbana do Rio de Janeiro. Sua localização nas proximidades dos centros de cultura e economia de serviços da cidade reforça sua função comercial, "além de reforçar a imagem de centro de "afazeres" da cidade" (VALVERDE, 2009, p. 26). Lotado de músicos de rua, camelôs, capoeiras, paIhaços, malabaristas, pastores e outros religiosos, é um território de imensa dinâmica social e identitária. Sendo uma das saídas mais movimentadas do Metrô que corta a cidade, lotado de sedes de pequenos estabelecimentos empresariais e autônomos, o fluxo diário de seus circunstantes nas rotinas de trabalho é imenso (VALVERDE, 2009).

A variedade de atividades e corpos normativos e desviantes inscritos no espaço impõe a percepção de que existem - e de certa forma, até resistem ao processo hegemônico em voga - dinâmicas econômicas peculiares, em grande parte construídas em razões afetivas e territoriais.

De certa maneira, esta condição de invisibilidade é correlata às descritas das políticas de patrimônio na área central da cidade, cuja trajetória acentua sua dimensão material. O trajeto Largo/Rua da Carioca expõe uma singularidade ao processo de requalificação em andamento na cidade do Rio de Janeiro quando envolvidas as dimensões imateriais do patrimônio. De certa forma, a Rua da Carioca apresenta-se como um "espaço en- tre" ofertas isotópicas de intervenção no espaço e práticas heterotópicas de relacionalidades espaciais.

Esta evidente tensão viria a se mostrar ainda mais dramática no contexto da produção espacial da região central nos anos 2010. É essencial recordar que a cidade do Rio de Janeiro recebeu uma agenda de megaeventos durante esta década e isto implicou incisivamente no modo de acumulação de sua economia urbana (VAINER, 2016).

Esta agenda também sintetiza uma série de alterações no padrão de planejamento urbano, amplamente discutido pela literatura crítica do espaço (ARANTES; VAINER; MARICATO, 2000; BROUDEHOUX, 2007; GOLD, 2008; MARSHALL, 2000; SÁNCHEZ, 2010). Quer-se chamar atenção para um novo parâmetro de interesses que se organiza a partir do crescimento da renda agregada ao uso do solo urbano, unindo grupos privados aos diferentes poderes estatais. A gestão urbana será formulada em grande parte para garantir diferentes maneiras de intensificação de extração de rendimentos privados que o espaço propicia (FERREIRA, 2003). No caso em questão, o centro da cidade seria um dos marcadores preferenciais para tal.

Este modelo de interposições refletirá também nos vínculos entre a materialidade patrimonial e a imaterialidade das práticas patrimoniais, que viria a se mostrar frágil diante das estratégias capitalistas de acumulação urbana. As propriedades imobiliárias da Rua da Carioca estavam disponíveis à liquidez do capital especulativo imobiliário em voga no cenário de requalificação do centro da cidade do Rio de Janeiro, os pequenos comércios que ocupavam estas propriedades, viam-se fragilizados diante deste processo. Até então, os valores de locação de grande parte dos imóveis na Rua 
da Carioca tinham ajustes baixos para o padrão do mercado imobiliário disponível no Centro, após negociação entre os comerciantes e a Venerável Ordem Terceira de São Francisco da Penitência (VOT) - proprietária dos imóveis.

Bem próximo à Praça Tiradentes, que à época já se encontrava em intenso processo de ocupação de serviços criativos, e um dos espaços-chave para a vinculação entre requalificação urbana isotópica e o campo cultural, a Rua da Carioca explicitaria uma gama de tensões para a vida patrimonial da cidade. Outrora pertencentes à VOT, dezenove casarões do lado ímpar da Rua da Carioca foram adquiridos em lote pelo Banco Opportunity ainda em 2013.

Segundo notícias da época, os investimentos do Banco visavam retomar a "aura de sofisticação" da Carioca, cuja ocupação seria destinada a escritórios "estilizados", segundo o diretor do Banco, Jorge Monnerat ${ }^{\vee}$. Em sendo, é de se supor que, ao lado das atividades comerciais que construíram certa anterioridade no local, outros comerciantes populares fossem empecilhos à nova estilização proposta. Vários deles anunciavam o receio de revisão dos preços dos aluguéis, o que tornaria a permanência de suas atividades impraticável ${ }^{\mathrm{VI}}$.

E nesta operação incide uma nova relação de poderes territoriais. Tendo como primado a dimensão financeira, do tráfego mais veloz possível em direção à acumulação urbana, certos laços até então consolidados no "espaço entre" da Carioca seriam submetidos a um novo tipo de "incorporeidade" do poder, fisicamente inacessível aos que não possuem os convites de entrada (BAUMAN, 2001).

Onde se pressupunha que as concorrências e acordos oficiais da constelação sócio-espacial específica produzissem relações contratuais correspondentes, viram-se posteriormente obstaculizados pela sensação de "novos negócios" que a posse dos capitais fixos concediam. Por óbvio, os interesses de um banco em nada se parecem com os de instituições religiosas que de certa forma marcam a própria história do lugar. Como tal, vizinhos indesejáveis ou inoportunos aos novos vínculos de desejo negocial a se construir serão substituídos por outros.

\section{Um novo livro para o patrimônio cultural: a tradição como um recurso de permanência espacial?}

Os efeitos deste processo têm desdobramentos para além da lógica empreendedora urbana. De alguma maneira, é a própria diversidade social um axioma da dimensão urbana - que pode ser reduzida ao isolamento e homogeneidade espacial produzidos pelo tipo de produção capitalista no espaço. É comum à lógica de aceleração rentista da acumulação urbana condicionar a dispersão espacial em moldes seletivos de expressões culturais, garantindo a segurança de uma "monótona similaridade de todos dentro do campo visual" (BAUMAN, 2001, p. 54).

Como tal, nota-se que as proteções patrimoniais em voga à época que tendiam a lidar quase que exclusivamente com a perspectiva material do patrimônio - mostravam-se desmobilizadas para interromper o fluxo de acumulação capitalista via monopólio espacial. Ademais, é essencial reafirmar como se imiscuem relações de acumulação de certos setores capitalistas aos interesses e investimentos públicos no empreendedorismo urbano. Indicado no plano estratégico Pós-2016 o processo de transformação da área central da cidade 
encontra na Prefeitura do Rio de Janeiro o principal agente de atração de capitais especulativos (PEC, 2010).

Ao ampliar o investimento em intervenções urbanas sem disponibilizar a mesma atenção na ampliação da participação popular na discussão e acompanhamento dos projetos urbanísticos de intervenção ou de medidas públicas para a interrupção dos processos de gentrificação (SMITH, 2006), os efeitos incidirão de forma mais decisiva à maior rentabilidade possível ao capital. Com isso, vê-se a possibilidade de constituição de um tempo produtivo do espaço que rechaça os corpos desviantes, agora em evidente risco.

De igual forma, é necessário interpelar dimensões patrimoniais possíveis no âmbito das relações entre economia criativa e o espaço urbano. Alguns arranjos produtivos compreendidos como parte da economia criativa podem dispor de maior ou menor facilidade para ingressar em ambientes onde a produtividade espacial se constrói como uma regra padrão da acumulação urbana. Arranjos mais afeitos a linguagens próximas à noção de inovação - portanto, capazes de oferecer serviços especializados - são alvos preferenciais dos investimentos em estilização adequados ao consumo global e aos processos de sobrevalor imateriais espaciais.

De maneira correlata, certas experiências patrimoniais, que se veem com menor propensão a contribuir para a acumulação destes atores capitalistas, não podem prescindir do diálogo com avizinhamentos que permitem reduzir os custos materiais de sua própria reprodução. Nesta razão, é possível supor que algumas canastras e seus atores preferenciais conquistam não apenas a simpatia dos investidores da requalificação espacial, como também as capacidades inerentes a se apresentarem como seus usuários mais adequados.

Há de se indagar, portanto, as diferentes capacidades de mobilidade que os sujeitos sociais detém ante seu acúmulo - alto ou não - de relações comunitárias e associativas (BAUMAN, 2001). É possível supor que alguns grupos sociais mais ativos em sua aproximação com classes rentistas conseguem mobilizar mais capitais necessários ao deslocamento espacial que outros. Em oposição, sujeitos sociais que dispõem de menos capitais (econômicos ou culturais) para deslocar-se precisam requisitar meios de reafirmação de seus vínculos territoriais e culturais para definir sua permanência no espaço.

É também neste sentido que a experiência patrimonial encontra na cidade seu lugar de disputas entre os possíveis sentidos a se conceber territorialmente. Este apanágio imerso em contradições demonstra vínculos entre os que se mostram indesejáveis à condição empreendedora da urbanidade, mas que podem resistir reivindicando ser parte ativa na memória compartilhada pelos habitantes da cidade.

Durante os anos de 2013 e 2014, os contratos de locação da Rua da Carioca foram sendo reajustados segundo os valores do mercado imobiliário corrente no período. É perceptível que os dispêndios anteriores de locação ofertados pela VOT contribuíam de forma decisiva para amenizar os custos fixos de reprodução do próprio comércio na região. A expansão da especulação imobiliária na área central, tendo em vista o já citado acúmulo de renovação das franjas da Rua da Carioca, contribuiu para construir um cenário de dificuldades para a permanência dos comerciantes na Rua.

Em entrevistas, vários comerciantes referiam-se ao reajuste dos preços 
de locação como uma medida sumária de sua expulsão da Carioca e também denunciavam não terem sido preferenciados na possibilidade de aquisição individual dos imóveis, tal como rege a lei. Já no mês de abril de 2013, nove lojistas estariam envolvidos com notificações de despejo, após correção locatária feita pelo BancoVII. É difícil supor que as medidas de reajuste fossem conexas a qualquer expectativa de máxima liquidez em relação aos investimentos de aquisição dos imóveis.

Em face disso, os comerciantes ali instalados procuraram organizar-se para impedir os riscos de despejo, utilizando, em especial, argumentos que recuperassem dimensões afetivas e patrimoniais da cidade. A Sociedade Amigos da Rua da Carioca e Adjacências (SARCA) promoveria então uma série de ações para a publicização do caso. Amplamente divulgado pela imprensa oficial e pela rádio informal que corta todo o ambiente, a Rua da Carioca veria ainda seus imóveis lotados com várias faixas que denunciavam a questão.

Neste momento entra em cena um curioso personagem, o senhor Roberto Cury. Citado pelos lojistas como o principal articulador dos comerciantes na busca por sua permanência no local, o Senhor Cury é membro fundador e Presidente da SARCA no momento do imbróglio. Também comerciante e extremamente articulado e carismático, Roberto Cury é um tipo muito específico de militante. Em entrevista, ele deixava claro que a Sociedade fora criada em 1977 em função de um projeto do período Lacerda para demolição do lado ímpar e de recuo do lado par da Rua da Carioca, que viabilizaria uma via expressa do centro ao bairro da Tijuca. Segundo Cury, já era interesse da Ordem Terceira a derrubada do local, onde seria possível a construção de dois espigões de prédios, mais rentáveis ${ }^{\mathrm{VIII}}$.
A resposta da Prefeitura implicou na maior novidade em termos de políticas patrimoniais na década. Procurando antecipar-se à questão, a Prefeitura do Rio de Janeiro, no Decreto 37.271, de 12 de junho de 2013, cria, após pronunciamento favorável do Conselho Municipal de Proteção do Patrimônio Cultural do Rio de Janeiro, o Livro de Registro de Atividades Econômicas Tradicionais e Notáveis (RIO DE JANEIRO, 2013a). O texto do Decreto indica que os livros de registro patrimoniais que até então orientavam os parâmetros das políticas de patrimônio imaterial (Saberes; Formas de expressão; Celebrações; e Lugares) não abrangiam as especificidades das atividades.

Como complemento, e através do Decreto 37.273, de 12 de junho de 2013, a Prefeitura do Rio de Janeiro, considerando "a importância da Rua da Carioca para a história e memória cultural da Cidade" e "o expressivo número de imóveis reconhecidos oficialmente como de valor cultural para a cidade", criou o Sítio Cultural da Rua da Carioca, tomba nove imóveis, e registra as nove atividades comerciais nestes situados no novo livro de Atividades Econômicas Tradicionais e Notáveis: Casa Nova Zurita; Irmãos Castro; Mala de Ouro; Mariu's Sport; Padaria e Confeitaria Nova Carioca; Ponto Masculino; Loja Vesúvio; A Guitarra de Prata; e, o Bar Luiz (RIO DE JANEIRO, 2013b).

O que se deriva é uma contradição entre vínculos possíveis de transmissão pública da noção acionada de "tradição" e sua legitimidade associada à permanência destes atores sociais em um espaço em vias de transformação. Ao determinar uma nova categoria como elemento fundacional de um novo livro de registro - no caso, a ideia associada de um comércio de pequena escala à tradicionalidade notável - a Prefeitura define como parâmetro de associação os seguintes critérios cumulativos: i) "em- 
presas que possuem uma marca ou reputação reconhecida"; ii) "empresas familiares que preservam o negócio entre gerações", iii) "comércios que preservam técnicas e processos de produção artesanais ou tradicionais"; e iv) "que sejam reconhecidos símbolos ou como parte da história da cidade do Rio de Janeiro"Ix.

É certo que os que parecem socialmente legitimados para exercer o sentido de classificação do mundo patrimonial estão nos informando algo. Se acionam alguma extensão ou renovação da noção de "tradição" é porque esta invenção parece explicitar a necessidade incessante da própria modernidade em atualizar seu parâmetro de informação social de tempo (GIDDENS, 2000).

A crença produzida, no entanto, desloca um certo parâmetro expressivo da performance até então entendida no vínculo patrimonial. Não se trata mais das coisas que intuímos serem de "antigamente", não apenas as que nos convencemos serem "originais" ou atemporais, cujo domínio de anterioridade é para alguns poucos seletos.

Vimos descrito em nossa frente que agora assumem como performance tradicional concedida por estatuto legitimado alguns "novos" corpos. Corpos que nunca necessitaram - ou nunca dominaram estas formas específicas de associação - acionar de forma explícita o que a normatividade estatal define como a "tradição" que move a arqueologia das políticas de patrimônio cultural.

O incrível é perceber que estes corpos novo-associados à tradição notável são já corpos endurecidos, gerenciais, pragmáticos e facilmente reconhecidos pelo próprio capital. Não são corpos facilmente deslocáveis do discurso patrimonial ao possível espetáculo - outro nível de associação da vida capital. São corpos já privados, rotineiros, fixados no tempo. Quando informados de sua tradicionalidade não sabem o que dela realizar.

Como percebido, a despeito dos vínculos ao patrimônio material consolidados tanto pela legislação municipal quanto pela estadual, os imóveis permaneciam à mercê do capital imobiliário e especulativo. De certa maneira, o processo lembraria o ocorrido na região central da cidade durante as décadas de 1990 e de 2000.

A diferença fundamental é que a Rua da Carioca se trata de um polígono com ativação territorial única, com cotidianidade afetiva amplamente difundida entre os citadinos, mesmo os que buscam entretenimento noturno ou alternativo. Portanto, um dos principais argumentos retóricos utilizados para justificar intervenções deste tipo - no caso, a degradação ou o esvaziamento espacial - perderia seu sentido de naturalização e legitimidade de atuação. $O$ que pressupunha a liquidez de investimentos privados, aproveitando-se dos investimentos públicos na área, em nada lembraria a onda de "revitalização" com a qual as franjas da Rua da Carioca seriam rotineiramente celebradas, mas a sumária condenação aos que não participam diretamente do projeto de acumulação urbana em processo.

No caso da criação do Livro Atividades Econômicas Tradicionais e Notáveis, é necessário igualmente estabelecer alguns comentários. Já foi citado o interesse expresso da Prefeitura do Rio de Janeiro em conceber uma nova realidade de ocupação do solo na área central da cidade, tendo inclusive a cultura como um de seus eixos especiais (PEC, 2010).

Mas existe um evidente hiato entre as expectativas dos gestores públicos $\mathrm{e}$ 
os que conferem materialidade à rotina de certas atividades patrimoniais. Desta maneira, a transição do patrimônio cultural ao conjunto de canastras que expressam a economia criativa não se dá de maneira simplificadora, como se poderia supor. Para concretizar-se, seria essencial conceber os diferentes tipos de programas de educação patrimonial complementares e os respaldos jurídicos que preservariam o comércio tradicional em relação à dinâmica espacial corrente.

Como tal, desde a criação do Sítio Cultural da Rua da Carioca, entre idas e vindas, dois estabelecimentos foram removidos do circuito. O Ponto Masculino conseguiu, em juízo, a compra de seu imóvel até então alugado. Resolvida sua pendência, seus donos sequer se interessaram em conceder depoimento sobre a participação no Sítio. A Mala de Ouro fechou as portas. Em entrevista concedida em junho de 2013, o senhor Henrique Cardoso, um dos sócios do empreendimento, reclamava da ineficácia do decreto e anunciava que os estabelecimentos ainda corriam os riscos de despejo. Extremamente comovido, dizia não entender qual o real efeito do novo livro de registro para a resolução do impasse e ainda desconhecer os planos do Banco Oportunnity para os imóveis ${ }^{\mathrm{X}}$.

No mês de abril de 2014 a SARCA convocou os comerciantes a performarem um ato simbólico de enterro da Rua da Carioca. Milhares de circunstantes puderam acompanhar uma pequena fanfarra executar a marcha fúnebre, enquanto os lojistas e outros simpatizantes impediam o tráfego normal dos automóveis. A despeito das inúmeras falas de apoio dos citadinos que listavam um abaixo-assinado a ser entregue à Prefeitura, e dos muitos apelos ao Banco em considerar a inscrição dos estabelecimentos na memória da cidade, o caso permanecia sem solução aparente.
Este fato expõe as dificuldades que os instrumentos de proteção ao patrimônio cultural até então disponíveis têm quando interpelados pela razão empreendedora urbana.

Eis uma curiosa associação: o ritual da morte performatizada demonstrava de forma bastante explícita como agências em risco apelam à associação de um corpo que já não mais se move ou respira. O enterro da Rua da Carioca reatualiza a percepção de que são os corpos que dão significado ao espaço. Um livro patrimonial parece guardar apenas a expectativa de registrá-los.

O grau de desânimo e descrença faz supor que a adesão ao novo livro de registro só poderia se fazer na incorporação de outros mecanismos da legislação urbana disponível. A principal demanda dos estabelecimentos registrados não estava ligada diretamente ao universo patrimonial, embora fosse este um argumento para atração afetiva dos citadinos. Foi constantemente citado que o pleito à Prefeitura era claramente a desapropriação dos imóveis e a indenização ao bancox!

O Decreto $n^{\circ} 38.645$, de 2 de maio de 2014, declara de utilidade pública, para fins de desapropriação, os imóveis $7,15,17,19,21,35$, e 37 da Rua da Carioca (RIO DE JANEIRO, 2014). Estavam desde já excluídos o Ponto Masculino por óbvio não se tratar de fins de desapropriação deste tipo - e a Mala de Ouro, com suas atividades já encerradas.

Neste desenrolar, percebe-se que a eficácia do novo livro de registro do patrimônio imaterial cede em relação à dinâmica de acumulação urbana na cidade empreendedora. Sem a disponibilidade de estratégias complementares, o simples ato de registro de atividades não carrega em si as competências su- 
ficientes para a continuidade da comunidade detentora de sua especificidade memorial ante a tensa relação entre propriedade privada e função social da cidade. Ademais, quando conduzidas sem o comum entendimento dos sujeitos sociais ativos da expressão patrimonial - de forma a estender e potencializar dinâmicas da referência cultural -, inclusive investindo na melhor adequação do texto de lei e no esclarecimento dos reais motivos de sua adequação, o registro parece dever muito mais à reprodução da "retórica da perda" (GONÇALVES, 1996) do que à real ativação do patrimônio e de suas especificidades na economia espacial. Igualmente, não há nenhum caráter explícito de como será empenhada a gestão dos imóveis, nem planos de envolvimento destes empreendimentos agora registrados em modelos de desenvolvimento econômico que estejam de acordo com suas atividades patrimoniais.

\section{Contratempos do espaço: tradição e produtividade espacial}

Procura-se aqui, nesta discussão final, indagar as relações entre empreendedorismo urbano, patrimônio cultural e a abertura de um novo livro patrimonial sob uma mudança escalar radical. O vínculo até aqui proposto procurou interpelar generalizações da gestão contemporânea da cidade e os níveis de construção e legitimação das políticas patrimoniais. Como tal, se demonstrou como as relações entre patrimônio material e imaterial adquirem níveis de enfrentamento da questão urbana razoavelmente desiguais no âmbito da política patrimonial da cidade do Rio de Janeiro.

Em que pesem as formas ideais apresentadas no texto, que procuram sinalizar a Rua da Carioca como um espaço entre perspectivas isotópicas e práticas heterotópicas, é necessário questionar-se quantas sobreposições espaciais são passíveis de se encontrar no processo. Empregando entrevistas com vários dos comerciantes e trabalhadores dos estabelecimentos erguidos à condição de atividade econômica notável, pode-se perceber como, em sua percepção, são ainda frágeis as relações do patrimônio com a cidade.

Foi curioso notar como, em suas falas, o tempo e o medo articulam-se mutuamente. Ao mesmo passo em que o tempo é o registro de ativação de sua legitimidade patrimonial como uma oposição ao rentismo imobiliário, é o medo de sua desconexão espacial em um Rio de Janeiro que parece não contrair mais sentido no atual estágio da acumulação urbana.

Traz para a discussão a necessidade de se pensar padrões de temporalidades compostas na análise. A inexorabilidade das relações espaço-tempo impõe ao registro do novo livro patrimonial um desafio de alta monta. Dado que as concepções de espaço e tempo são criações fundamentais da ação humana e servem à reprodução da vida social (HARVEY, 2004), o registro das condições notáveis da economia local só podem ser condicionadas às variáveis espaciais sobre as quais estes registros temporais se mostram consolidados, fazendo o esforço de recuo histórico no acompanhamento de sua trajetória até o tempo presente. Em sendo, é apenas na contínua captura e interpretação das narrativas dos atores-chave componentes destas atividades que se mostrará possível perceber em qual grau a inexorabilidade descrita se relaciona com forma mais contemporânea de espacialização do empreendedorismo urbano.

Este nexo que faz supor que a Rua da Carioca não se trata apenas de 
um "espaço entre", mas essencialmente de um espaço que conecta tempos, temporalidades e corporalidades "entre". De certa maneira é esta conexão entre os efeitos da isotopia (que estes comerciantes também fazem apropriar-se, evidentemente) às diversas perspectivas heterotópicas vizinhas.

Vale aqui registrar de imediato que o tempo da produtividade do capital, do rentismo e da liquidez imediata não se vale das mesmas categorias sociais que os citadinos ora representantes do comércio da área constroem para si em relação à cidade. Desta feita, o que parece conduzir parte das contradições descritas não é apenas o apego das classes capitalistas aos negócios urbanos e à máxima lucratividade, mas igualmente a assincronia entre registros de experimentação de tempos e espaços sociais em choque no espaço. Nestas estão incluídas formas capitais não corporificadas - ativos financeiros -, cuja relação com o espaço se dá em máxima aceleração de seu valor, em detrimento de formas de oferta de serviços, grande parte consolidados numa dada economia de afetos espaciais, em nada capazes de antepor-se nas condições de acumulação de agentes financeiros.

Aparentemente destino irremediável da acumulação, a Rua e o Largo da Carioca atuam como lacunas. Um espaço que não se comove à velocidade desta acumulação, e que teima em residir em outro aspecto temporal. Como tal, os sujeitos que usufruem de sua fisicalidade respondem aos anseios de renovação espacial como espectros. Aparentemente inadequados ao tempo proposto pelo capital ou pelo produtivismo criativo, repousa em suas falas a ausência de perspectivas sobre o poder público, e mais propriamente o receio da perda ou inadequação. Servem como que indutores silenciados de uma história em vias de ser ressignificada, aparentemente tardios no modelo atual de produção espacial.

Implicitamente, dedicou-se até aqui a explicitar como o espaço é construído de forma desigual pelos sujeitos sociais. No caso em questão, é na posse imobiliária - como direito constituído de propriedade - e nos vínculos patrimoniais - como seleção induzida das políticas culturais - onde se fará perceber com mais evidência a maneira diferenciada de ação no espaço.

Desta feita, ainda que ressaltando o grau novidadeiro do novo livro patrimonial, é em sua perspectiva de atuação não incisiva no espaço seu laço mais preocupante. Atuações diferentes no espaço dizem também respeito às perspectivas diferentes de futuro do espaço. A aceleração da produtividade do solo - no caso em questão expresso na especulação imobiliária em nada parece adequar-se às atividades que ainda presenciam uma certa nostalgia comercial local.

Como mediador no campo político, a procura da Prefeitura do Rio de Janeiro em equacionar a questão a partir da abertura de um novo livro de registro mostrou-se problemática, em parte porque os registros foram estabelecidos na perspectiva de permanência dos comerciantes e trabalhadores no local. Nas entrevistas produzidas com os comerciantes cujas práticas foram registradas no livro de Atividades Econômicas Notáveis, em nenhum momento se fizeram animados com o fato, estando cientes de que a questão demandava outro acento da legislação urbana corrente. O novo livro demonstrara, portanto, pouco valor até o momento em que designou os imóveis como de interesse público. Apenas na perspectiva da posse imobiliária que o imbróglio parece resolver-se.

Se um dos interesses da Prefeitura fora aproximar a perspectiva patrimo- 
nial ao universo gerencial da economia criativa, traduzindo a aproximação entre cultura e negócios urbanos, este se fez em certo desacordo à concepção patrimonial vigente no centro da cidade do Rio de Janeiro pós-década de 1980. Se nesta fase da política patrimonial da cidade fora consolidada a perspectiva de um conjunto urbano a se proteger, impedindo o lastro de descaracterização imobiliária e paisagística dos mercados futuros de construção civil e da especulação, esta nova ação - que congrega ao mesmo passo um novo livro de registro patrimonial e o Sítio Cultural da Rua da Carioca - foi produzida não de maneira a interpor-se aos anseios especulativos, mas de minimizar seus efeitos. A dimensão requerida de Sítio também precisa ser melhor problematizada.

Ao percorrer a Rua da Carioca percebe-se nitidamente que outros tantos imóveis se mostrariam face de um conjunto mais denso à atividade patrimonialXII. Como tal, a escolha dos nove empreendimentos, o encerramento das atividades da Mala de Ouro, a desistência do Ponto Masculino em fazer parte do conjunto, fazem crer que o conjunto de iniciativas finalmente concebidas no nível do novo livro de registro mostra-se menos um sítio e mais um aglomerado de iniciativas atomizadas. Em sendo, reflete novas formas-fetiche patrimoniais, em nada construídas na relação território-cidade-economia urbana. Dá-se que sua produção discursiva - uma tradição notável - parece ter sido concebida nesta gestação como uma aderência ao desespero de ver estes corpos e estas agências potencialmente removidas do cotidiano suportável de um espaço disponível à acumulação urbana com base especulativa. O que vemos hoje, alguns anos após a iniciativa da Prefeitura e em momento de entrave do capitalismo no Brasil, é que o vazio da Rua da Carioca expõe a opção do discurso do pa- trimônio cultural como uma metonímia irrealizável ${ }^{X I I I}$.

Com relação à dinâmica espaço-tempo, este processo poderá gerar desafios ainda mais complexos à permanência de outros "sujeitos econômicos notáveis". A necessidade de eleição de tradições econômicas notáveis e sua fixação num ponto espacial, que ora projeta um novo avizinhamento, não faz dos arranjos econômicos destas iniciativas - em geral, arranjos com fluxo de caixa não elevado, e de caráter mais popular necessariamente desejáveis aos detentores das propriedades imobiliárias. $\mathrm{Na}$ dinâmica dos "tempos entre", o tempo "passado" fixado nos empreendimentos notáveis e o tempo "futuro" de renovação do padrão de acumulação parecem concorrentes. Ademais, viceja-se também a descaracterização do conjunto urbano na sua totalidade. Se o anterior avizinhamento das tradições constitui-se em dinâmicas que não se consolidavam por mediação de livros patrimoniais, é de difícil suposição que as próximas terão a benemerência da tradição em despeito da máxima acumulação possível aos que dominam a produção do espaço.

\section{Bibliografia}

ANDREATTA, Verena. Atlas Andreatta: Atlas dos planos urbanísticos do Rio de Janeiro - de Beaurepaire-Rohan ao Plano Estratégico. Rio de Janeiro: Vivercidades, 2008.

ARANTES, Otília; VAINER, Carlos; MARICATO, Ermínia. A cidade do pensamento único: desmanchando consensos. Petrópolis, RJ: Vozes, 2000.

BAUMAN, Zygmunt. Globalização: as conseqüências humanas. Tradução Marcus Penchel. Rio de Janeiro: Jorge Zahar, 1999. 
BRENNER, Neil; MARCUSE, Peter \& MAYER, Margit (org). Cities for People, not for Profit: Critical Urban Theory and the Right to the City. New York; Londres: Routledge, 2011.

BROUDEHOUX, Anne-Marie. Spectacular Beijing: the Conspicuous Construction of an Olympic Metropolis. Journal of Urban Affairs, 29 (4), 2007

COMPANS, Rose. Empreendedorismo Urbano: entre o discurso e a prática. São Paulo: UNESP, 2004.

DOMINGUES, João. A história institucional recente da política de patrimônio cultural na cidade do Rio de Janeiro: versões protecionistas, versões empreendedoras. Antíteses, Londrina, v. 9, 2016, p. 222-245.

DOMINGUES, João. Marketing urbano e a dimensão da criatividade: colonização iminente do capitalismo flexível?. Latitude (UFAL), v. 6, p. 191-214, 2013.

FERREIRA, João Sette Whitaker. São Paulo: 0 mito da cidade-global. (Tese em Arquitetura e Urbanismo). Universidade de São Paulo, 2013.

GIDDENS, Anthony. As conseqüências da modernidade. Tradução de Raul Fiker. São Paulo: Editora da Universidade Estadual Paulista, 1991.

GOLD, John R.; GOLD, Margaret M. Olympic Cities: Regeneration, City Rebranding and Changing Urban Agendas. Geography Compass, Londres, 2008, p. 300-318.

GONÇALVES, José Reginaldo Santos. A Retórica da Perda: os discursos do patrimônio cultural no Brasil. Rio de Janeiro: Editora UFRJ; IPHAN, 1996.

HARVEY, David. A produção capitalista do espaço. São Paulo: Annablume, 2006.

HARVEY, David. Condição Pós-Moderna: uma pesquisa sobre as origens da mudança cultural. São Paulo: Loyola, 2004.

LEFĖBVRE, Henri. A revolução urbana. Belo Horizonte: Editora UFMG, 1999.

MARSHALL, Tim. Urban planning and governance: is there a Barcelona model? International Planning Studies, v. 5, n. 3, p. 299-319, 2000.

PECRJ. Plano Estratégico da Cidade do Rio de Janeiro: Pós-2016, O Rio mais integrado e competiti- vo, 2010. Disponível em <http://www0.rio.rj.gov.br/ planoestrategico/>. Acesso em 21 nov. 2017.

SÁNCHEZ, Fernanda. A reinvenção das cidades para um mercado mundial. Chapecó, SC: ARGOS, 2010.

SMITH, Neil. A gentrificação generalizada: de uma anomalia local à "regeneração" urbana como estratégia urbana global. In: BIDOU-ZACHARIASEN (ed.). De volta à cidade: dos processos de gentrificação às políticas de "revitalização" dos centros urbanos. São Paulo: Annablume, 2006. p. 59-87.

VAINER, Carlos. Mega-eventos, Cidade de Exceção e Democracia Direta do Capital: reflexões a partir do Rio de Janeiro. In: VAINER, Carlos; BROUDEHOUX, Anne Marie; SÁNCHEZ, Fernanda; OLIVEIRA, Fabrício Leal (orgs). Os Megaeventos e a Cidade: perspectivas críticas. Rio de Janeiro: Letra Capital, 2016, p.19-46.

VALVERDE, Rodrigo. Largo da Carioca como um cenário: da representação da publicidade à projeção espacial da informalidade. Geousp, v. 25, p. 22-40, 2009.

Decretos:

RIO DE JANEIRO (Município). Decreto n. 38.645, de 2 de maio de 2014. Declara de utilidade pública, para fins de desapropriação, os imóveis que menciona. Diário Oficial do Município do Rio de Janeiro, Poder Executivo, 2014.

RIO DE JANEIRO (Município). Decreto $n$. 20.048, de 11 de junho de 2001. Altera os $\S \S$ 50 e 60 e cria os $\S \S 70$ e 80 do Artigo 81 do Regulamento de Licenciamento e Fiscalização aprovado pelo Decreto 3.800 , de 20 de abril de 1970. Diário Oficial do Município do Rio de Janeiro, Poder Executivo, 2001.

RIO DE JANEIRO (Município). Decreto n. 37.271, de 12 de junho de 2013. Determina a abertura do Livro de Registro das Atividades Econômicas Tradicionais e Notáveis. Diário Oficial do Município do Rio de Janeiro, Poder Executivo, 2013a.

RIO DE JANEIRO (Município). Decreto $n$. 37.273, de 12 de junho de 2013. Cria o Sítio Cultural da Rua da Carioca, tomba os imóveis que menciona, e dá outras providências. Diário Oficial do Município do Rio de Janeiro, Poder Executivo, 2013b. 


\section{Recebido em 24/11/2017 Aprovado em 24/02/2018}

I João Luiz Pereira Domingues. Doutor em Planejamento Urbano e Regional pela Universidade Federal do Rio de Janeiro/IPPUR. Professor Adjunto III do Departamento de Arte, do Curso de Graduação em Produção Cultural e do Programa de Pós-Graduação em Cultura e Territorialidades da Universidade Federal Fluminense. Líder do Grupo de Pesquisa "Cultura, Política e Território”, cadastrado na base de dados do CNPQ. Contato: joaolpdomingues@gmail.com.

II O presente artigo é uma versão atualizada de um trabalho publicado nos anais do XVII Encontro Nacional da Associação Nacional de Pós-Graduação e Pesquisa em Planejamento Urbano e Regional, e um dos resultados parciais das pesquisas "Rua da Carioca: usos do patrimônio cultural como fonte de repertórios da economia criativa", contemplada na Chamada n. 80/2013 CNPq/SEC/MinC, e "A articulação entre políticas urbanas e políticas culturais: o empreendedorismo urbano e o patrimônio cultural na zona portuária do Rio de Janeiro", contemplada pelo Programa Jovens Cientistas do Nosso Estado, da FAPERJ.

III A economia criativa é uma ideia-força que no Brasil foi anunciada como um certo tipo de organização de arranjos produtivos com "potencial" de geração de valor extraído de propriedades intelectuais ligadas a atividades expressivas e linguagens artísticas. Em se tratando de uma razoável novidade de animação das relações entre o campo cultural e o campo econômico, esta ideia-força detém uma série de interpretações, que em nossa interpretação interagem majoritariamente com o ciclo histórico do capitalismo flexível. Para mais, ver Domingues (2013).

IV Para mais, ver <http://emendasesonetos.blogspot. com.br/2008/07/dos-magros-bucfalos-aos-burros-sem-rabo.html>. Acesso em 20 jul. 2017.

V Disponível em: <http://oglobo.globo.com/rio/um-reduto-criativo-na-praca-tiradentes-1-12763521>. Acesso em: 15 de setembro de 2016.

VI Disponível em: <http://brasil.estadao.com.br/noticias/geral,casaroes-do-centro-do-rio-na-mira-do-alto-luxo,934390>. Acesso em: 21 de outubro de 2016.
VII Disponível em: <http://oglobo.globo.com/rio/nove-lojistas-da-rua-da-carioca-recebem-ordem-de-despejo-8246595>. Acesso em: 19 de outubro de 2016.

VIII Entrevista de Roberto Cury a João Domingues, Mario Pragmácio e Rebeca Eler, 30 de maio de 2013.

IX Para mais, ver <http://www.rio.rj.gov.br/web/irph/ exibeconteudo?id=6411214>. Acesso em 24 jul. 2017.

$X$ Entrevista de Henrique Cardoso a João Domingues, 18 de junho de 2013.

XI Até o momento da finalização deste texto não havia nenhuma confirmação do pagamento de indenização ao Banco Opportunity e nem seu valor final. Segundo a legislação vigente, a declaração de utilidade pública demanda pagamento de indenização para fins de desapropriação, cuja caducidade tem validade de 5 anos.

XII Em especial o Cine Iris e o Cine Ideal, imóveis que não fazem parte do conjunto adquirido pelo Banco Opportunity.

XIII Sobre o vazio de ocupação comercial da Rua da Carioca, ver <http://g1.globo.com/rio-de-janeiro/ noticia/comercio-em-crise-g1-percorre-a-rua-da-carioca-e-ve-1-loja-fechada-a-cada-10-metros.ghtml>. Acesso em 23 jul. 2017. 